Utah State University

DigitalCommons@USU

2000

\title{
Dynamic Environmental Policy in Developing Countries in the Presence of a Balance of Trade Deficit and a Tariff
}

\author{
Amitrajeet A. Batabyal \\ Utah State University \\ Hamid Beladi \\ Dug Man Lee \\ Utah State University
}

Follow this and additional works at: https://digitalcommons.usu.edu/eri

\section{Recommended Citation}

Batabyal, Amitrajeet A.; Beladi, Hamid; and Lee, Dug Man, "Dynamic Environmental Policy in Developing Countries in the Presence of a Balance of Trade Deficit and a Tariff" (2000). Economic Research Institute Study Papers. Paper 200.

https://digitalcommons.usu.edu/eri/200

This Article is brought to you for free and open access by the Economics and Finance at DigitalCommons@USU. It has been accepted for inclusion in Economic Research Institute Study Papers by an authorized administrator of DigitalCommons@USU. For more information, please contact digitalcommons@usu.edu.

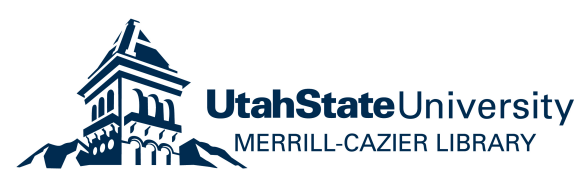


Economic Research Institute Study Paper

ERI \#2000-24

\section{DYNAMIC ENVIRONMENTAL POLICY IN DEVELOPING \\ COUNTRIES IN THE PRESENCE OF A BALANCE OF}

TRADE DEFICIT AND A TARIFF

by

AMITRAJEET A. BATABYAL

Department of Economics

Utah State University

3530 Old Main Hill

Logan, UT 84322-3530

HAMID BELADI

Department of Economics and Finance

University of Dayton

300 College Park

Dayton, OH 45469-2251

DUG MAN LEE

Graduate Research Assistant

Department of Economics

Utah State University

3530 Old Main Hill

Logan, UT 84322-3530

June 2000 
DYNAMIC ENVIRONMENTAL POLICY IN DEVELOPING

COUNTRIES IN THE PRESENCE OF A BALANCE OF

TRADE DEFICIT AND A TARIFF

\author{
Amitrajeet A. Batabyal, Associate Professor \\ Department of Economics \\ Utah State University \\ 3530 Old Main Hill \\ Logan, UT 84322-3530 \\ Hamid Beladi, Professor \\ Department of Economics and Finance \\ University of Dayton \\ 300 College Park \\ Dayton, OH 45469-2251 \\ Dug Man Lee, Graduate Research Assistant \\ Department of Economics \\ Utah State University \\ Logan, UT 84322-3530
}

The analyses and views reported in this paper are those of the author(s). They are not necessarily endorsed by the Department of Economics or by Utah State University.

Utah State University is committed to the policy that all persons shall have equal access to its programs and employment without regard to race, color, creed, religion, national origin, sex, age, marital status, disability, public assistance status, veteran status, or sexual orientation.

Information on other titles in this series may be obtained from: Department of Economics, Utah State University, 3530 Old Main Hill, Logan, Utah 84322-3530.

Copyright (C) 2000 by Amitrajeet A. Batabyal, Hamid Beladi, and Dug Man Lee. All rights reserved. Readers may make verbatim copies of this document for noncommercial purposes by any means, provided that this copyright notice appears on all such copies. 


\title{
DYNAMIC ENVIRONMENTAL POLICY IN DEVELOPING COUNTRIES IN THE PRESENCE OF A BALANCE OF TRADE DEFICIT AND A TARIFF Amitrajeet A. Batabyal, Hamid Beladi, and Dug Man Lee
}

\begin{abstract}
We first review the literature pertaining to the protection of the modern sector in developing countries (DCs). We then discuss the nexuses between protection, economic dualism, and optimal environmental policy in DCs. Next, in the theoretical part of the paper, we construct a dynamic model of the environmental policy formulation process in a stylized DC in which there is a balance of trade deficit, and a tariff that protects the modern-also the import competing and the polluting - sector. The employment and output effects of three different pollution taxes are analyzed. These taxes incorporate different assumptions about the DC government's ability to commit to its announced course of action. The taxes are characterized, the dependence of these taxes on the extant tariff is studied, and the conditions which call for an activist policy, irrespective of the length of time to which the government can commit to its announced policy, are specified. Our analysis shows that the dynamic inconsistency of some optimal programs and the existence of the tariff can — either singly or collectively — prevent the DC government from attaining its employment and environmental goals.
\end{abstract}

JEL classification: O20, Q20

Key words: commitment, developing country, environmental policy, tariff, trade deficit 


\section{DYNAMIC ENVIRONMENTAL POLICY IN DEVELOPING COUNTRIES IN THE PRESENCE OF A BALANCE OF TRADE DEFICIT AND A TARIFF ${ }^{1}$}

\section{Introduction}

\subsection{Protection in developing countries}

It is a well known historical fact that the world's three largest market economies all began their industrialization behind trade barriers. In particular, the United States and Germany both protected their manufacturing industries in the nineteenth century. More recently, Japan has had import controls on a variety of products up until the 1970s. The combination of this historical fact and the appeal of certain theoretical arguments have led many developing countries (DCs) to embrace the infant industry argument for temporary protection of the manufacturing sector against import competition. By actively following a policy of encouraging import substituting industrialization, DCs have attempted to improve their balance of payments positions and develop their manufacturing industries. ${ }^{2}$ We now briefly describe the experiences of four DCs that have actively protected their domestic manufacturing industries. ${ }^{3}$

\footnotetext{
${ }^{1}$ We thank Mohan Munasinghe and Osvaldo Sunkel for inviting us to contribute a paper to this volume. Batabyal and Lee acknowledge financial support from the Utah Agricultural Experiment Station, Utah State University, Logan, UT 84322-4810, by way of grants UTA 024 and 010, respectively. Approved as journal paper \#7189. This paper's findings complement the analysis contained in Batabyal and Beladi (1999). The usual disclaimer applies.

${ }^{2}$ For more on trade policy in developing countries, see Bhagwati and Srinivasan(1979), Krueger (1984), Rodrik (1988), and Krugman and Obstfeld (1994, chapter 11).

${ }^{3}$ The subsequent description of the structure of protection in the four DCs borrows heavily from the individual country studies in Balassa and Associates (1971).
} 


\subsubsection{Brazil}

Balassa and Associates (1971, p. 105) have noted that import "substitution has been crucial in Brazilian industrialization." In the mid-1960s, only $4 \%$ of the domestic consumption of manufactured goods was provided by imports. Although immediately before World War II, Brazilian manufacturing was heavily concentrated in food products and textiles, by 1964, the share of metals and metal products in manufacturing output was $31 \%$, the share of chemicals was $17 \%$, and the share of food products and textiles had declined to $36 \%$ of the total. In addition to this, the research of Bergsman (1970) tells us that in Brazil, throughout the 1960s, manufacturing industries - in particular electrical equipment and plastics - were heavily protected.

\subsubsection{Mexico}

In Mexico, since 1955, "the main objective of trade policy has been the protection of domestic industry..." (Balassa and Associates, 1971, p. 179). To this end, a large and complicated system of tariffs and import licenses have been used to protect a variety of domestic industries. In 1960, import competing manufactured goods were favored with 59\% effective tariff protection and import competing manufactured goods excluding tobacco and beverages were granted $31 \%$ effective tariff protection. As a result of this level of protection, there "is growing concern for the high cost [that] the continuation of import-substituting industrialization entails and the limits to which it is subject." (Balassa and Associates, 1971, p. 200).

\subsubsection{Pakistan}

In 1947, virtually all manufactured goods in Pakistan were imported and agricultural products were exported. Since the late 1940s and the early 1950s, Pakistan's trade policy has involved the systematic use of quantitative restrictions on imports. Moreover, Pakistan's trade policy 
has discriminated among producers. For instance, in 1963-1964, the effective implicit protection granted to the privileged producers of certain kinds of steel products was $177 \%$. The comparable rate of protection granted to firms without import privileges was $81 \%$. As another example, consider the case of automobile manufacturers, all of whom enjoyed import privileges. The effective implicit protection granted to these manufacturers was 514\%. As Balassa and Associates (1971, p. 232) have remarked, Pakistan's "restrictive trade policy...turned the terms of trade sharply against the agricultural sector, and benefitted the domestic producers of manufactures as well as import licensees who were permitted to import and sell manufactured goods."

\subsubsection{The Philippines}

The adoption of import controls in 1949 led to considerable growth in the production of manufactured goods. As Golay (1961, chapter 8) has noted, since 1957, the Tariff Law has become the principal instrument of protection. In particular, tariffs have gradually increased with the average tariff on manufactured goods rising from $46 \%$ in 1961 to $51 \%$ in 1965 . A number of manufacturing industries were granted very high rates of protection in a representative year such as 1965 . Here are two examples: Producers of structural iron and steel were afforded an effective rate of protection of at least $300 \%$. Clay tile producers were granted an effective rate of protection of around $250 \%$. These and other similar figures have led Balassa and Associates (1971, p. 280) to conclude that "manufacturing is heavily protected when compared with the other major sectors."

The four cases that we have focused on so far support the following general claim: The embrace of the infant industry argument by DCs has led them to use trade policy to systematically protect the manufacturing sectors of their economies. Inter alia, the use of trade policy in this way has often exacerbated the problem of economic dualism in DCs. Consequently, let us now examine 
the connections between trade policy and the phenomenon of economic dualism.

\subsection{Dualism in developing countries}

An economy in which there are "two sectors that appear to be at very different levels of development..." (Krugman and Obstfeld, 1994, p. 264) is referred to as a dual economy. Many DCs can usefully be described and analyzed as dual economies. This is because in these DCs, a modern, high-wage, industrial sector exists alongside a traditional, low-wage, agricultural sector. As is well known, this wage differential can and often does play the role of a magnet that draws labor from the low-wage, traditional sector into the high-wage, modern sector. ${ }^{4}$

The problem of unplanned labor migration that this wage differential gives rise to has been much studied in the development economics literature. ${ }^{5}$ Given the joint existence of protectionist trade policies and this phenomenon of unplanned labor migration, the relevant question for our purpose is this: Does protection of the manufacturing sector increase the likelihood that laborers/workers will migrate from the traditional sector to the modern sector in search of high-wage jobs? As we have seen in our country case studies in section 1.1, protection of the manufacturing sector generally leads to an expansion in the output of this sector. In turn, this expansion in output can be expected to increase the demand for labor in the manufacturing sector, and thereby increase the wage in the manufacturing sector. This means that the protection of the manufacturing sector will, ceteris paribus, strengthen the incentives for migration from the low-wage, traditional sector to the high-wage, modern sector. Indeed, as Krugman and Obstfeld (1994, p. 268) have noted, the

\footnotetext{
${ }^{4}$ For more on economic dualism and its labor market implications, see Harris and Todaro (1970), Sen (1975, 1980), and Schuh (1982).

${ }^{5}$ The literature on migration in developing countries is vast. In addition to the sources cited in the previous footnote, see Johnstone (1983) for Malaysia, DeJong et al. (1983) for the Philippines, Yang (1993) for China, and Dang et al. (1997) for Vietnam.
} 
problem of "dualism...may be worsened by import restrictions, especially those undertaken in the name of import substitution."

Thus far we have seen that in the post World War II era, a number of DCs have protected their manufacturing sectors and that many of these same DCs have been afflicted by the problems — such as migration — of a dual economy. In the past two decades, and particularly since the publication of the Brundtland Report (1987), there has been great interest in the question of sustainable development. Researchers now generally agree that if the development process is to be sustainable, then DCs will need to implement policies that protect their environmental resources adequately.

The design of such "environment friendly" policies is complicated by the fact that in many DCs, the protected manufacturing sector is also the polluting sector. Consequently, the institution of optimal environmental policy in such a setting involves a careful analysis of the nexuses between the trinity of trade protection, economic dualism, and pollution.

\subsection{Protection, dualism, and pollution in developing countries}

Three issues relating to the conduct of environmental policy in DCs have increasingly come to dominate public debate in large parts of the developing and the developed world. As Miller (1995) and others have noted, the first issue is the perception in many developed countries that DCs are not doing enough to protect their environmental resources. The second issue concerns the need for creating employment opportunities in DCs. In this connection, researchers such as Batabyal (1987), Bhalla (1992), Renner (1992), and Mehmet (1995) agree that DC governments must make a concerted attempt to design and implement policies that generate employment.

The third issue concerns the apparent tradeoff between employment creation and 
environmental protection. As indicated in section 1.2, scholars now agree that in addition to implementing employment creating policies, in order to protect the environment, DC governments will also have to implement apposite environmental policies. The experience of industrialized nations with environmental policies tells us that these policies can have a negative effect on employment (Christainsen and Tietenberg, 1985; Bonetti and FitzRoy, 1999). This and other similar findings have led many to argue that in the face of pressing employment creation needs, DC governments are unlikely to be serious about environmental protection. Put differently, although DC governments may initiate the process of establishing environmental policies, their commitment to such policies is likely to be limited.

In order to address this protection/migration/pollution issue rigorously, it is necessary to analyze a dynamic model that explicitly links a DC government's period of commitment to its announced employment/environmental policies. To the best of our knowledge, with two exceptions, this kind of model, and indeed this issue, has not been analyzed formally in the literature. ${ }^{6}$ Recently, Batabyal (1998) and Batabyal and Beladi (1999) have analyzed dynamic models of environmental policy in dualistic DCs. In a two sector model, Batabyal (1998) shows that the welfare gain from correcting for pollution is generally larger than the welfare loss from being unable to commit to a particular environmental policy. Consequently, optimality calls for the DC government to conduct an activist environmental policy, regardless of the length of time to which this government can commit to its announced policy. Batabyal and Beladi (1999) have extended this analysis and examined the properties of intertemporal environmental policy when the polluting (and the import competing) sector of the $\mathrm{DC}$ is protected with an import tariff. In this situation, they show that there

${ }^{6}$ For a more detailed corroboration of this claim, see Lekakis (1991) and Mehmet (1995). 
are a number of circumstances in which the optimal pollution tax equals the existing tariff.

In the Batabyal and Beladi (1999) paper, initially, the DC economy is in disequilibrium and there is a surplus in the balance of trade account. In this paper, we analyze the case in which initially, the DC economy is in disequilibrium and the balance of trade account is in deficit. The specific question that we address is the following: What is the nature of optimal environmental policy when (i) the DC's balance of trade account is initially in deficit, (ii) the DC government corrects for pollution by taxing the production of the good manufactured by the protected sector, and (iii) this government is not necessarily able to commit to the tax policy that it announced at the beginning of its tenure in office? As we shall see, whether there is a surplus or a deficit in the balance of trade account at time $\boldsymbol{t}=\mathbf{0}$ has significant implications for the nature of optimal environmental policy.

The rest of this paper is organized as follows: In section 2, we describe the theoretical framework in detail. In sections 3 through 5, we analyze a dynamic model of the conduct of environmental policy by the government of a stylized DC, under three different assumptions about the ability of this government to commit to its initially announced policy. Section 6 concludes and offers suggestions for future research.

\section{The Theoretical Framework}

Our model is in the tradition of papers such as Pindyck (1982), Karp and Paul (1994), Batabyal (1998), and particularly Batabyal and Beladi (1999), which study the implications of government policies in a dynamic framework. We use the Ricardo-Viner model to study a small DC. In keeping with the discussion in section 1, we suppose that this DC's economy is dualistic. Specifically, the two DC sectors consist of a modern, high-wage, environmentally intensive manufacturing sector in which production causes pollution. This polluting sector is also the import 
competing sector of the economy. A pre-existing tariff protects this sector. Following the discussion in section 1.1, the reader may want to think of this sector as the "infant industry" of the DC. The second sector is the traditional, low-wage, environmentally benign sector in which there is no pollution. This traditional sector-possibly the agricultural sector-is the DC's export sector. Because of political factors, the DC government is unable to remove the tariff any time in the foreseeable future. Consequently, in the rest of this analysis, we treat the tariff as a parameter.

The prospect of earning higher wages induces workers to migrate from the traditional sector to the modern sector. This migration results in increased employment in the modern sector, increased production, and hence greater pollution. In their role as consumers, workers are adversely affected by pollution. Nevertheless, they do not factor pollution into their migration decisions. As a result, the marginal migrant pays less than the marginal social cost of unplanned migration. In this situation, the first best policy is to tax pollution directly. However, in many DCs, the government simply does not possess the wherewithal to tax pollution directly. Consequently, we suppose that the DC government operates in a second best environment in which it controls pollution by taxing the production of the polluting good.

Initially, the government does nothing to correct distorted producer incentives. Consequently, the DC economy is in disequilibrium and the balance of trade account is unbalanced. As indicated in section 1.3 and in contrast with the case analyzed in Batabyal and Beladi (1999), in this paper, we suppose that initially this account is in deficit. A movement toward equilibrium requires a reduction in the production of the polluting good over time. Put differently, a move toward equilibrium involves slowing the rate at which workers migrate from the traditional sector to the modern sector. We assume that workers have rational expectations. In our deterministic model, this means that workers have perfect foresight. 
Each sector of the $\mathrm{DC}$ produces one good with a fixed factor and a mobile factor called labor, with decreasing returns to scale. Superscripts on production variables will denote the sector and superscripts on consumption variables will denote the agent. Subscripts will denote partial derivatives. $L^{i}(t), i=1,2$, is the labor employed by the $i t h$ sector at time $t$; time is continuous. We have $L^{1}(t)+L^{2}(t)=\hat{L}$, where $\hat{L}$ is the DC's fixed endowment of labor. Good 2 is the import competing and the polluting good. Let $\tau_{e}(t)$ denote the existing tariff which protects sector 2 . The government's environmental policy instrument is a pollution tax, $\tau_{p}(t)$, which is levied on the production of good 2. Following Batabyal (1998) and Batabyal and Beladi (1999), we use duality theory to model consumption and production decisions in the DC. The production function in the ith sector, $i=1,2$, is $f^{i}\left(L^{i}\right)$. Let the world price of good 2 be $p=p^{2} / p^{1}$, where $p^{1}=1$. Further, let $L^{2}=L$, and let $L^{1}=\hat{L}-L$. Finally, denote the revenue functions in the two sectors by $R^{1}(1, \hat{L}-L)$ and $R^{2}\left(p+\tau_{e}-\tau_{p}, L\right)$, respectively. It is clear that $R_{1}^{i}(\cdot)$ and $R_{2}^{i}(\cdot)$ denote the output supply of good $i$ and the wage in sector $i$, respectively. ${ }^{7}$

There is a continuum of identical workers in each sector of the DC economy and a single capitalist is the residual claimant. All agents have homothetic preferences. As such, following Dixit and Norman (1980, p. 326), the expenditure function of agent $j, j=1,2,3$, can be written as $\bar{E}\left(p+\tau_{e}, 1, u^{j}\right)=U^{j} E\left(p+\tau_{e}\right)$, where $E(\cdot)$ is the unit expenditure function and $U^{j}$ is agent $j^{\prime} s$ real income. National income for the DC is $U \equiv(\hat{L}-L) U^{1}+L U^{2}+U^{3}$. The superscript $j$ stands for the representative worker in sector $j=1,2$, and $j=3$ denotes the capitalist.

Denote the private value of migration for any worker at time $t$, by $m(t)$. So $m(t)$ is the discounted value of the wage differential between the high-wage polluting sector and the low-wage

\footnotetext{
${ }^{7}$ For more on the properties of these dual functions, see Dixit and Norman (1980, chapter 2).
} 
traditional sector. Mathematically, we have

$$
m(t)=\int_{t}^{\infty} e^{-r(s-t)}\left\{R_{2}^{2}(\cdot)-R_{2}^{1}(\cdot)\right\} d s,
$$

where $r$ is the discount rate. The integral equation in (1) can be converted into a differential equation. That equation is

$$
\dot{m}=r m+R_{2}^{1}(\cdot)-R_{2}^{2}(\cdot) .
$$

A worker will migrate to the modern sector if and only if the private value of migration, $m(t)$, is at least as high as the private cost of migration. However, because workers do not factor pollution into their migration decisions, the social cost of migration is not equal to the private cost of migration. Let the social cost of migration be quadratic, i.e., $C(\dot{L})=\alpha(\dot{L})^{2}$, where $\alpha>0$. Because the average social cost of migration, $\alpha \dot{L}$, is less than the marginal social cost, $2 \alpha \dot{L}$, in the absence of government intervention, migration for high-wage employment in the polluting sector takes place too rapidly, thereby increasing environmental degradation. To model the fact that the social cost of migration exceeds the private cost, suppose that workers base their migration decision on a fraction $\delta, \delta \in(0,1)$, of the marginal social cost $2 \alpha \dot{L}$. Put differently, the migrating workers do not internalize the externality stemming in part from their decision to migrate. Now let us equate the private value of migration with the private cost of migration. This gives us an equation for the dynamics of labor migration. That equation is

$$
\dot{L}=\frac{m}{2 \alpha \delta} \text {. }
$$

Our DC's economy is open and we are disallowing the possibility of international borrowing. This 
means that in equilibrium, trade must be balanced. In other words, we must have

$$
D\left(U, L, m, \tau_{e}, \tau_{p}\right)=U E(\cdot)+\frac{m^{2}}{4 \alpha \delta^{2}}-R^{1}(\cdot)-R^{2}(\cdot)-\tau_{e}\left[U E_{1}(\cdot)-R_{1}^{2}(\cdot)\right]+\tau_{p} R_{1}^{2}(\cdot)=0
$$

The first term in this "balance of trade deficit" expression refers to consumption expenditures. Equation (3) tells us that $C(\dot{L})=m^{2} / 4 \alpha \delta^{2}$. Hence, the second term on the RHS of equation (4) denotes the social cost of pollution. The third and the fourth terms give the value of production. The fifth term denotes the tariff revenue. Finally, the sixth term denotes the pollution tax revenue. As indicated in section 1.3 , initially, i.e., at time $\boldsymbol{t}=\mathbf{0}$, the balance of trade account is in deficit. This means that expenditures exceed revenues. This is why we have added and not subtracted the pollution tax revenue $\left(\tau_{p} R_{1}^{2}(\cdot)\right)$ in equation (4). We assume that the tax revenues are redistributed in lump sum fashion.

Our objective now is to study the DC government's optimal dynamic environmental policy under three assumptions about its ability to commit to a particular course of action. In the first case, the government commits to a tax trajectory for an infinite period of time. The reader should interpret this infinite period of commitment as a case in which environmental protection is enshrined in the constitution. ${ }^{8}$ When this is done, it does not matter which government is in office because the mandates of the constitution will have to be followed. In the second case, the DC government commits to a tax trajectory for a finite period of time. This finite period of commitment is more reasonable and it should be thought of as the length of time during which a particular government is in office. Unfortunately, in both these cases, the government's optimal tax policy is dynamically

\footnotetext{
${ }^{8}$ As Batabyal (1998) has noted, if the DC in question were India, the beginning of this period would be 1976. This is because until 1976, environmental protection did not figure anywhere in the Indian constitution.
} 
inconsistent. To comprehend this, consider the tax trajectory which the government announces at time $\boldsymbol{t}=0$. Dynamic inconsistency means that at some time $\varepsilon>0$, the government will want to deviate from the trajectory that it announced at $t=0$. As a result, the government's announced policy at time $t=0$ will not be credible. This means that forward looking workers will not believe that the government will actually carry through with its initially announced policy. Hence this policy will fail to attain its intended goals.

Since the credibility of government policy has been an important issue in many DCs, $a$ priori, it would seem essential to study the implications of the DC government following a dynamically consistent course of action. ${ }^{9}$ This is the third case that we study. In this case, the government commits to its tax policy for an infinitesimal period of time. In the limiting case, the period of commitment approaches zero, and the government's tax policy is dynamically consistent. This completes the discussion of our theoretical framework. We now examine the DC government's problem when it commits to its tax policy for an infinite period of time.

\section{Environmental Policy with Infinite Commitment}

In this case, the DC government makes a binding commitment and chooses its tax trajectory over $[0, \infty]$ at time $t=0$. In the terminology of control theory, this is the government's open loop tax policy. The open loop pollution tax is a function of calender time only. Recall that workers have perfect foresight and that they are forward looking. Because the economy is in disequilibrium at $t=0$, the initial value of $L, L(0)=L_{0}$, does not equal the stationary state value of labor in the polluting sector of the economy. Further, the decision to migrate is an investment decision. Consequently, the

\footnotetext{
${ }^{9}$ Recall the section 1.3 discussion of the concern as to the lack of commitment in DC government policies. For more on this, see Fanelli et al. (1992).
} 
private value of migration at any time $t, m(t)$, is determined by the current and the future values of the pollution tax. This means that the equation (2) actually represents a jump state constraint. ${ }^{10}$ Formally, this means that the initial value of $m, m(0)$, is endogenous to the problem. This feature of the model makes the government's optimization problem a non-standard control problem. In this setting, the DC government solves

$$
\max _{U, \tau_{p}} \int_{0}^{\infty} e^{-r s} U d s
$$

subject to equations (2)-(4), with initial condition $L(0)=L_{0}$. The current value Hamiltonian for this problem is

$$
\mathrm{H}=U-\lambda\left[U E+\frac{m^{2}}{4 \alpha \delta^{2}}-R^{1}-R^{2}-\tau_{e} U E_{1}+\tau_{e} R_{1}^{2}+\tau_{p} R_{1}^{2}\right]+\sigma_{1}\left\{\frac{m}{2 \alpha \delta}\right\}+\sigma_{2}\left\{r m+R_{2}^{1}-R_{2}^{2}\right\},
$$

where $\lambda$ is the Lagrange multiplier on constraint (4), and $\sigma_{1}, \sigma_{2}$ are the costate variables corresponding to constraints (3) and (2), respectively. The first order necessary conditions are

$$
\begin{gathered}
\lambda=\frac{1}{E\left(p+\tau_{e}\right)-\tau_{e} E_{1}\left(p+\tau_{e}\right)}, \\
\lambda\left\{\left(\tau_{e}+\tau_{p}\right) R_{11}^{2}(\cdot)-2 R_{1}^{2}(\cdot)\right\}+\sigma_{2} R_{21}^{2}(\cdot)=0, \\
\dot{\sigma}_{1}=r \sigma_{1}+\sigma_{2} h(\cdot)+\lambda\left\{d(\cdot)+\left(\tau_{e}+\tau_{p}\right) R_{12}^{2}(\cdot)\right\},
\end{gathered}
$$

and

$$
\dot{\sigma}_{2}=\frac{\lambda m}{2 \alpha \delta^{2}}-\frac{\sigma_{1}}{2 \alpha \delta}
$$

\footnotetext{
${ }^{10}$ Many problems in economics are characterized by the existence of jump states. In monetary economics, the exchange rate is generally a jump state because it is affected by current interest rates and agents' expectations of the future money supply. For more on jump state constraints, see Karp and Newbery (1993), Karp and Paul (1994), and Batabyal (1996a, 1996b).
} 
where $d(\cdot) \equiv R_{2}^{1}(\cdot)-R_{2}^{2}(\cdot)$, and $h(\cdot) \equiv R_{22}^{1}(\cdot)+R_{22}^{2}(\cdot)$. That is, $-d(\cdot)$ denotes the current private value of migration, and $h(\cdot)$ denotes the sum of the slopes of the marginal products of labor in the two sectors. Note that $h(\cdot)=\partial\{-d(\cdot)\} / \partial L<0$.

Our main interest lies in characterizing the optimal pollution tax trajectory, and in studying the dependence of this tax on the tariff $\tau_{e}(t)$. To this end, let us denote stationary values by the superscript $S$. From equation (3), it follows that $m^{S}=0$. From equation (2), we get $d^{S}(\cdot)=0$. Equation (10) implies that $\sigma_{1}^{S}=0$. From equation (8) it follows that $\sigma_{2}^{S}=\left[-\lambda\left\{\left(\tau_{e}+\tau_{p}\right) R_{11}^{2}-2 R_{1}^{2}\right\} / R_{21}^{2}\right]^{S}$. From equation (9), we get $\sigma_{2}^{S}=\left[-\lambda\left(\tau_{e}+\tau_{p}\right) R_{12}^{2} / h\right]^{S}$. Setting these last two expressions equal, we get $\tau_{p}^{S}=\left[\left[\tau_{e}\left\{R_{12}^{2} R_{21}^{2}-R_{11}^{2} h\right\}+2 R_{1}^{2} h\right] /\left[R_{11}^{2} h-R_{12}^{2} R_{21}^{2}\right]\right]^{S}$. From equation (8), it follows that $\tau_{p}(t)=\left[\left[\lambda(t)\left\{2 R_{1}^{2}-\tau_{e}(t) R_{11}^{2}\right\}-\sigma_{2}(t) R_{21}^{2}\right] / \lambda(t) R_{11}^{2}\right]$. Because $m(0)$ is free, as Simaan and Cruz (1973) have noted, the right boundary condition for $\sigma_{2}$ is $\sigma_{2}(0)=0$. This means that the $\mathrm{DC}$ government chooses its tax trajectory so that the social shadow value of $m$ at the beginning of the program is zero. Using $\sigma_{2}(0)=0$, we get $\tau_{p}(0)=\left[\left\{2 R_{1}^{2} / R_{11}^{2}\right\}-\tau_{e}(0)\right]$.

\subsection{Analysis}

Inspection of the expressions for $\tau_{p}(0), \tau_{p}(t)$, and $\tau_{p}^{S}$ from the previous paragraph tells us that in an optimal program, the government's pollution tax depends on the existing tariff $\tau_{\boldsymbol{e}}$, in a rather complicated manner. In order to shed more light on this dependence and on the nature of the government's optimal program, we now use specific functional forms and analyze two special cases.

First, suppose that the revenue function in the second sector of the DC is separable in its arguments. Then the cross-partial derivatives of this revenue function vanish. Now substitute $R_{12}^{2}(\cdot)=R_{21}^{2}(\cdot)=0$ in the expressions for $\tau_{p}(0), \tau_{p}(t)$, and $\tau_{p}^{S}$ to get 


$$
\tau_{p}(0)=\frac{2 R_{1}^{2}(0)}{R_{11}^{2}(0)}-\tau_{e}(0), \tau_{p}(t)=\frac{2 R_{1}^{2}(t)}{R_{11}^{2}(t)}-\tau_{e}(t), \tau_{p}^{S}=\frac{2 R_{1}^{2}(S)}{R_{11}^{2}(S)}-\tau_{e}^{S}
$$

Second, consider the case in which the sector 2 revenue function is quadratic and separable in its arguments. Then $R_{12}^{2}(\cdot)=R_{21}^{2}(\cdot)=0$ and $R_{11}^{2}(\cdot)=k$, a constant. Substituting these three values in the expressions for $\tau_{p}(0), \tau_{p}(t)$, and $\tau_{p}^{s}$, we get

$$
\tau_{p}(0)=\frac{2 R_{1}^{2}(0)}{k}-\tau_{e}(0), \tau_{p}(t)=\frac{2 R_{1}^{2}(t)}{k}-\tau_{e}(t), \tau_{p}^{S}=\frac{2 R_{1}^{2}(S)}{k}-\tau_{e}^{S}
$$

Equations (11) and (12) tell us that whether we look at the beginning of the program, at some intermediate point in the program, or in the stationary state, the pollution taxes in all three instances are qualitatively similar in both the cases. Specifically, these taxes equal the ratio of twice the supply of the polluting good to the slope of the supply curve for the polluting good less the value of the tariff, all evaluated at the appropriate points in time. This ratio that we have just identified will generally be positive. Thus, the pollution taxes will be positive if and only if the magnitude of this ratio exceeds the magnitude of the existing tariff. If this last condition holds, then our DC government's open loop tax policy is activist in the sense that it is optimal to tax the production of the polluting good at all points in the program.

Equations (11) and (12) also tell us that at a specific point in the program, it is possible for the pollution tax to be zero, or even negative. This stands in sharp contrast to the analogous result in Batabyal and Beladi (1999). In that paper, the optimal open loop pollution tax is never negative, and $\forall \boldsymbol{t}>0$, the pollution tax is positive. Whereas in this paper, with an initial balance of trade deficit, a large tariff can make the pollution tax zero, or convert it into a subsidy, as demonstrated in Batabyal and Beladi (1999), this can never happen when there is a surplus in the balance of trade 
account at $\boldsymbol{t}=\mathbf{0}$. This tells us that the deficit or surplus status of the DC's balance of trade account at $\boldsymbol{t}=0$ has a salient effect on the government's optimal environmental policy.

In order to study the nature of the dependence of the optimal pollution tax on the existing tariff, let us differentiate the expressions for $\tau_{p}(t)$ from equations (11) and (12), holding $L$ and $p$ constant. This yields

$$
\frac{d \tau_{p}(t)}{d \tau_{e}(t)}=\frac{\left\{R_{11}^{2}(\cdot)\right\}^{2}-2 R_{1}^{2}(\cdot) R_{111}^{2}(\cdot)}{3\left\{R_{11}^{2}(\cdot)\right\}^{2}-2 R_{1}^{2}(\cdot) R_{111}^{2}(\cdot)}, \frac{d \tau_{p}(t)}{d \tau_{e}(t)}=\frac{1}{3} .
$$

The first derivative in equation (13) corresponds to $\tau_{p}(t)$ from equation (11) and the second derivative corresponds to $\tau_{p}(t)$ from equation (12). Intuitively, raising the tariff increases the wage differential between the two sectors and hence makes migration to the polluting sector more attractive. In turn, this increase in migration exacerbates the pollution problem. Consequently, we expect the sign of the derivatives in equation (13) to be positive. We see that although this is indeed the case when the revenue function is separable and quadratic $\left(d \tau_{p} / d \tau_{e}=1 / 3>0\right)$, in general, this expected positive relationship need not hold. In fact, equation (13) tells us that in the case in which the sector 2 revenue function is separable, if $\left\{R_{11}^{2}\right\} \leq 2 R_{1}^{2} R_{111}^{2}$, then the relationship between the pollution tax and the tariff will not be positive.

In this open loop case that we have been studying so far, there is no welfare loss to society from the government's inability to commit to its announced course of action. This is because the open loop policy incorporates perfect commitment. Consequently, the case for doing nothing — which potentially arises when the government cannot commit—is eliminated. Despite this, and contrary to the results contained in Batabyal and Beladi (1999), we have seen that the existence of the tariff means that the pollution tax is not unambiguously positive. 
From a policy credibility perspective, if the DC government's open loop tax policy is believed by the migrating workers, then this policy will attain its goals. In particular, if the pollution tax is positive, then this tax will reduce output and employment in the polluting sector and slow the rate of migration from the traditional sector to the polluting sector. However, the government's goals will not be attained because the government will have an incentive to deviate from the policy it announced at $t=0$. To see this, observe that for any initial value of $L, L(0) \neq L^{S}$, the optimal initial shadow value of $m(t), \sigma_{2}(t)$, is zero. However, because $\delta<1$, on the announced tax trajectory, $\sigma_{2}(t) \neq 0$. This means that at any time $\varepsilon>0$, the government will want to deviate from the tax trajectory it announced at $\boldsymbol{t}=0$, and announce a new trajectory. In other words, the government's open loop tax policy is dynamically inconsistent. This means that unless there is some means by which the DC government can be bound to its initially announced tax trajectory, this government will fail to attain its initially announced employment and environmental goals. This tells us that when the government uses an open loop tax policy, it may be doomed in two ways. First, the existing tariff can prevent it from attaining its policy goals. Second, even if there were no tariff, the dynamic inconsistency of this policy will certainly ensure that the government's policy goals are not attained.

From a practical standpoint, this case of perfect commitment is implausible because no government can realistically be expected to commit to its policy for an infinite period of time. Consequently, we now examine the case in which the DC government commits to its announced policy at $\boldsymbol{t}=0$, for a finite period of time. This is the limited commitment case.

\section{Environmental Policy with Limited Commitment}

Given that governments are in office for a finite amount of time, the most reasonable period of commitment corresponds to the length of time during which a particular government is in office. 
Consequently, let us now study the case of limited commitment in which the government commits to a policy for $T \in(0, \infty)$ periods of time.

When the period of commitment is finite, an analysis of the DC government's optimal program is complicated. This is because the ensuing equilibrium depends on the manner in which agents form their expectations. If migrants base their expectations of future taxes on the history of taxes, then multiple equilibria can arise. To obviate this problem, we shall restrict attention to smooth Markov perfect equilibria. By Markov we mean that the decision rules of the agents at any time $t$, depend only on the current value of the state (stock of labor), and not on the manner in which the current state was reached. A candidate for an equilibrium is perfect if this candidate is an equilibrium for any possible subgame (any possible level of the stock of labor). In particular, whether or not some agents have deviated from their equilibrium strategies in the past, the continuation of these strategies represents equilibrium behavior on the part of all the agents involved. From a practical standpoint, the Markov assumption is useful because it makes the DC government's optimal program insensitive to agents' mistakes.

With this restriction of Markov perfection, we can now describe the equilibrium that arises when the government commits to its tax policy for $T$ periods. At time periods $0, T, 2 T, \ldots$, successive governments choose their own tax policies. Put differently, at each $i T, i=0,1,2, \ldots$, the $i t h$ government completes its tenure in office and a new government chooses its tax policy for the next $T$ time periods. At the end of $T$ periods, each government bequeaths $L_{T}$, the current stock of labor, to its successor government. This government then pursues its environmental policy for the next $T$ periods, and so on.

With this interpretation of the limited commitment case, let $V(L)$ be the value of the government's program when its period of commitment is $T$ periods and when the initial level of 
labor in the polluting sector is $L$. The government now solves

$$
V(L)=\max _{\tau_{p}, U} \int_{0}^{T} e^{-r t} U d t+e^{-r T} V\left(L_{T}\right),
$$

subject to equations (2)-(4). Note that $V\left(L_{T}\right)$ is a bequest function. This function denotes the value of the stock of labor bequeathed by an arbitrary government to its successor. Also note that problem (14) is the same as the problem described in section 3, with the exception that the government's period of commitment is now $T$ as opposed to infinity. This means that the boundary condition at the horizon of the program will be different, although the first order necessary conditions themselves remain as in equations (7)-(10).

As in section 3 , the fact that $m(0)$ is free indicates that it is optimal to choose the tax trajectory so that $\sigma_{2}(0)=0$. Using this last condition in equation $(8)$, we get $\tau_{p}(0)=\left[\left\{2 R_{1}^{2} / R_{11}^{2}\right\}-\tau_{e}(0)\right]$. Also, as in section 3, $\tau_{p}(t)=\left[\left[\lambda(t)\left\{2 R_{1}^{2}-\tau_{e}(t) R_{11}^{2}\right\}-\sigma_{2}(t) R_{21}^{2}\right] / \lambda(t) R_{11}^{2}\right]$. Finally, to determine $\tau_{p}(T)$, let $M(L)$ be the equilibrium current value of $m$ that is determined by the solution to problem (14). ${ }^{11}$ In our case, we can write $V(L) \equiv \bar{V}\{L, M(L)\}$, for some function $\bar{V}\{\cdot\}$. At the beginning of a specific time period $i T, i=0,1,2, \ldots$, we have $\sigma_{2}(i T)=0$. Further, the assumed smoothness of the value function gives $\sigma_{2}=\partial \bar{V} / \partial M$ (Karp and Paul, 1994, p. 1388; Batabyal, 1998, p. 15). That is, the social shadow value of $M$ is equal to the marginal value of $M$ in the bequest. Finally, the transversality condition for $\sigma_{2}$ is $\sigma_{2}(T)=\partial \bar{V} / \partial M=0$. Using this condition in equation (8), we get $\tau_{p}(T)=\left[\left\{2 R_{1}^{2} / R_{11}^{2}\right\}-\tau_{e}(T)\right]$.

\subsection{Analysis}

Comparing the three tax expressions in the previous paragraph with the corresponding

\footnotetext{
"The properties of this endogenous function of the state have been discussed elsewhere and hence we omit an elaborate discussion. For more details, see Karp and Newbery (1991) or Karp and Paul (1994).
} 
expressions from section 3, it is clear that a diminution in the length of the government's period of commitment results in no qualitative change in either $\tau_{p}(0)$ or in $\tau_{p}(t)$. However, $\tau_{p}(T)$ differs from $\tau_{p}^{S}$ because of the altered boundary condition in the limited commitment case. In particular, the condition $\sigma_{2}(T)=0$, which does not apply in the perfect commitment case, can be used to simplify the expression for $\tau_{p}(T)$.

For the cases in which the revenue function in the polluting sector is separable, and quadratic and separable, the limited commitment pollution taxes are given by equations (11) and (12) respectively, with $S$ replaced by $T$. Consequently, the analysis of section 3.1 applies to this limited commitment case as well. In particular, the optimal pollution taxes at various points in the program are qualitatively similar, and the government's optimal program is activist in some circumstances. Once again, it is possible for the limited commitment pollution tax to be zero or negative at some points in the program. Finally, the optimal pollution tax depends on the tariff. However, contrary to expectation, the sign of this dependence is not always positive. As in section 3 , these results are at variance with the analogous results in Batabyal and Beladi (1999). This tells us that the DC government's ability to conduct environmental policy efficaciously is significantly affected—and possibly compromised - by the initial deficit/surplus status of the balance of trade account.

From the analysis in section 3.1 and the analysis thus far, the reader will note that when the polluting sector's revenue function is separable, or quadratic and separable in its arguments, whether commitment is infinite or limited has no bearing on the government's optimal course of action. This means that the pollution tax at all points in the program in both commitment scenarios is qualitatively similar. Put differently, the separability of the revenue function is a sufficient condition for the nature of commitment not to matter. 
Note the salient role played by the $M(L)$ function. This endogenous function of the state performs the role of an "expectations" function. When the DC government solves its optimization problem taking this expectations function as given, the optimal policy results in an initial value of $m, m(0)$, that satisfies $m(0)=M\{L(0)\}$. In other words, in equilibrium, every agent's point expectations are fulfilled. Further, this same optimal policy results in a terminal value of $m$ so that $\sigma_{2}(T)=\partial \bar{V}(\cdot) / \partial M=0$. This means is that at the horizon of the program, the shadow value of the state $M$, equals the marginal value of $M$ in the bequest function, and these two values equal zero.

Although this limited commitment case is plausible, the corresponding Markov perfect equilibrium is dynamically inconsistent. To see why, think of this Markov perfect case as one in which an infinite sequence of governments conducts environmental policy during a time period of length $T$. Let the term of office of each government in this sequence be denoted by $\{i T\}_{i=0}^{\infty}$. As long as $T>0$, each government behaves consistently at each $i$, but not within a period of length $T$. Put differently, the government begins its term in office with the best of intentions, but some time later, it will want to renege on the policy it announced at the beginning of its term in office. As a result, forward looking agents will not believe that the government will actually carry through with its initially announced policy. From a credibility perspective, this means that the government will not succeed in attaining its policy goals. In particular, even when optimality calls for an activist policy, pollution and employment in sector 2 will not be reduced, and the government will not succeed in slowing the rate of migration from the traditional sector to the polluting sector.

Thus far, we have seen that the extant tariff and the dynamic inconsistency of the government's optimal tax policy can prevent the DC government from attaining its employment and environmental goals. In this paper, we assumed that on account of political factors, tariff protection will always be provided to the import competing sector. Hence, nothing can be done to remove this 
trade tax. However, something can be done to eliminate the dynamic inconsistency of the government's optimal tax policy. We now do this by examining the case in which the DC government commits to its tax policy for an infinitesimal period of time. In this setting, we study the limiting Markov perfect equilibrium in which the government's period of commitment tends to zero. $^{12}$

\section{Environmental Policy with Infinitesimal Commitment}

Intuitively, one expects the Markov perfect equilibrium to depend on the government's period of commitment. Specifically, one expects the government's equilibrium tax to be a function of three factors. The first factor - the presence of pollution — would appear to necessitate an activist policy designed to address this external diseconomy. The second factor-the government's inability to commit to its tax trajectory-would appear to favor the status quo. The effect of the third factor - the existing tariff-is ambiguous. Given this state of affairs, the relevant policy question is this: When the government's period of commitment is infinitesimal, are there circumstances in which it is optimal to set a zero pollution tax?

To study the limiting case, we follow Karp and Paul (1994), Batabyal (1998), and Batabyal and Beladi (1999), and begin with a discrete stage formulation of the DC government's optimization problem. ${ }^{13}$ Denote this government's period of commitment, and the length of each stage, by $\varepsilon$. Further, suppose that all agents act at the beginning of each time period of length $\varepsilon$. The constraints facing the government at any time $t$ are

\footnotetext{
${ }^{12}$ For an alternate approach to the construction of dynamically consistent policies, see Batabyal (1996a, 1996b).

${ }^{13}$ See Karp and Newbery (1993) for additional details on the underlying methodology.
} 


$$
L_{t}=\left\{\frac{m_{t}}{2 \alpha \delta}\right\} \varepsilon+L_{t-\varepsilon}
$$

and

$$
m_{t}=e^{-r \varepsilon} m_{t+\varepsilon}-d_{t}(\cdot) \varepsilon,
$$

where $d_{t}(\cdot)=R_{2}^{1}(\cdot)-R_{2}^{2}(\cdot)$. In equation (15), $\left\{m_{l} / 2 \alpha \delta\right\} \varepsilon$ represents the number of migrants in a period of length $\varepsilon$. Similarly, in equation $(16),-d_{t}(\cdot) \varepsilon$ denotes the value of the flow of the wage differential in a time period of length $\varepsilon$. Note that equations (15) and (16) represent constraints (3) and (2) in discrete form. At time $t-\varepsilon$, with period of commitment $\varepsilon$, the government's dynamic programming problem is

$$
V\left(L_{t-\varepsilon}\right)=\max _{U, \tau_{p}}\left[U-\lambda\left\{D\left(U, L, m, \tau_{e}, \tau_{p}\right)\right\}\right] \varepsilon+e^{-r \varepsilon} V\left(L_{t}\right),
$$

subject to equations (15) and (16). Note that the function $D(\cdot)$ represents the balance of trade deficit constraint described by equation (4), that $m_{t+\varepsilon}=M\left(L_{t}\right)$, and that the government takes the function $M(\cdot)$ as given. After some algebra, the first order necessary condition w.r.t. $\tau_{p}$ can be expressed as

$$
\left[\lambda\left\{\left(\tau_{e}+\tau_{p}\right) R_{11}^{2}-2 R_{1}^{2}-\frac{\partial D}{\partial L_{t}} \cdot \frac{d L_{t}}{d \tau_{p}}-\frac{\partial D}{\partial m_{t}} \cdot \frac{d m_{t}}{d \tau_{p}}\right\}\right] \varepsilon+e^{-r \varepsilon} \frac{d V}{d L_{t}} \cdot \frac{d L_{t}}{d \tau_{p}}=0
$$

In order to simplify equation (18), let us differentiate equations (15) and (16) totally. This gives

and

$$
\frac{d L_{t}}{d \tau_{p}}=\frac{\varepsilon}{2 \alpha \delta} \cdot \frac{d m_{t}}{d \tau_{p}}
$$

$$
\left\{-h_{t}(\cdot) \varepsilon-e^{-r \varepsilon} \frac{d M}{d L_{t}}\right\} \frac{d L_{t}}{d \tau_{p}}+\frac{d m_{t}}{d \tau_{p}}=-\left\{\frac{\partial d_{t}(\cdot)}{\partial \tau_{p}}\right\} \varepsilon
$$

Now substitute for $d L l d \tau_{p}$ from equation (19) into equation (20) and then simplify the resulting equation. We get $d m_{l} / d \tau_{p} \sim O(\varepsilon)$. Similarly, substituting for $d m_{l} / d \tau_{p}$ from equation (20) into equation (19) and then simplifying the resulting equation yields $d L_{l} / d \tau_{p} \sim O(\varepsilon)$. Finally, divide both sides of equation (18) by $\varepsilon$, use the preceding two results regarding $d m_{l} / d \tau_{p}$ and $d L / d \tau_{p}$, and then let $\varepsilon \rightarrow 0$. 
The limiting first order necessary condition becomes

$$
\lambda\left\{\left(\tau_{e}+\tau_{p}\right) R_{11}^{2}-2 R_{1}^{2}\right\}=0
$$

\subsection{Analysis}

Equation (21) tells us that the limiting Markov perfect pollution tax $\tau_{p}=\left\{2 R_{1}^{2} / R_{11}^{2}\right\}-\tau_{e}$. We see that this limiting tax also depends on the tariff. Further, the presence of the tariff prevents us from answering the policy question that we posed at the beginning section 5, unambiguously. In Batabyal and Beladi (1999), the limiting Markov perfect pollution tax is always positive and equal in magnitude to the existing tariff. Here, we see that depending on the magnitude of the tariff, it is possible for the limiting tax to be zero, or even negative. As in sections 3 and 4, this tells us that the DC government's ability to conduct environmental policy effectively is significantly affected—and possibly compromised — by the initial deficit/surplus status of the balance of trade account.

Equation (21) also tells us that if there is no tariff, then the limiting pollution tax is unambiguously positive. In the beginning of section 5 , we noted that there are three factors which affect the pollution tax. Of these three factors, when the tariff factor can be dispensed with, the question of setting a zero tax reduces to a comparison of the welfare gain from correcting for pollution with the welfare loss from the government's inability to commit to its declared tax policy. Equation (21) tells us that even when the government displays no commitment to its tax policy, the welfare loss from being unable to commit is never as large as the welfare gain from reducing pollution. This is why the optimal pollution tax - in the absence of the tariff-is positive.

The limiting case that we analyzed in this section involves continuous revision of the pollution tax by the DC government. When the government revises its policy instrument continually, the resulting policy is dynamically consistent. Put differently, the government's tax policy is 
believable. However, equation (21) tells us that even with this believable tax policy, the government may not be successful in reducing pollution in the modern sector and in slowing the rate of migration from the traditional sector to the modern sector. This is because the tariff may result in the limiting tax actually being zero or even negative.

For the moment, let us set the tariff aside and focus on the credibility aspect of dynamic environmental policy. As Karp and Newbery (1993) have noted, the payoff to an agent is monotonic in his period of commitment. This means that reducing the government's period of commitment can never make this government better off. With this observation and the earlier discussion of policy efficacy in mind, it is possible to rank the three policies in term's of the government's preference, and the policy's ability to attain its goals. From the DC government's standpoint, the preferred policy is the open loop policy because this policy results in the highest payoff to the government. The second best policy is the Markov perfect tax policy with a finite period of commitment. The least preferred policy is the limiting Markov perfect tax policy. In contrast with this ranking, the ranking in terms of goal attainment is exactly the opposite. The limiting Markov perfect tax policy is credible. Consequently, this policy will be able to reduce pollution and slow migration to the polluting sector. The other two policy instruments are not believable; hence they will fail to attain the government's employment and environmental goals. This discussion highlights the DC government's quandary. The policy which results in the highest payoff to the government is the one that is least desirable from the standpoint of credibility.

\section{Conclusions}

In this paper, we used the Ricardo-Viner model to study a small, dualistic DC in which there is pollution, a balance of trade deficit, and a tariff. In particular, we studied the conduct of dynamic 
environmental policy by the DC government under three assumptions about this government's ability to commit to its announced policy. Four significant policy conclusions emerge.

First, the analysis of this paper tells us that there are two factors that might prevent a DC government from attaining its employment and environmental objectives. The first factor concerns the dynamic inconsistency of some optimal programs. Our analysis showed that as long as the private cost of unplanned migration is less than the social cost of unplanned migration, i.e., as long as $(\delta<1)$, the limiting Markov perfect tax policy is the only credible environmental policy. The second factor concerns the extant tariff. We showed that when the import competing sector is the polluting sector, the presence of the tariff may mean that the optimal pollution tax is zero, or even negative. Consequently, in terms of its effect on environmental policy, the tariff is not benign. Indeed, this tariff can have adverse consequences for the government's ability to conduct environmental policy successfully.

Second, our analysis shows that doing nothing, i.e., setting a zero pollution tax, is typically not an optimal course of action. We showed that except in knife-edge cases, the optimal response of the government to the existence of pollution will generally be to set non-zero taxes. We say nonzero and not positive because if the existing tariff is large, then it is possible for the pollution tax to be, in effect, a subsidy.

Third, from the standpoint of policy credibility alone, our analysis points to the impractical nature of dynamically inconsistent, particularly open loop, policies. Such policies cannot be believed by forward looking agents with rational expectations. Therefore, these agents will successfully thwart the DC government's policy objectives. This stands in sharp contrast to the limiting Markov perfect tax policy which is dynamically consistent. In this case, the equilibrium is characterized by an endogenous function of the state and the government continuously revises its tax trajectory. 
Continuous revision implies credibility and this in turn means that the government's environmental policy will attain its intended goals.

Fourth, there is a basic tradeoff between policy credibility and policy payoff. Credible policies yield a lower payoff than do non-credible policies. This observation provides a possible explanation as to why many DC governments are loath to use dynamically consistent policies which necessitate continuous policy revision.

The analysis contained in this paper can be extended in a number of directions. In what follows, we suggest two possible extensions. First, one can change the migration equation - equation (3) - so that the decision to migrate depends on $m$ and the tax $\tau_{p}$. Second, one can analyze the conduct of dynamic environmental policy in a setting in which the traditional (non-polluting) sector is affected by one or more distortions. Studies which incorporate these aspects of the problem into the analysis will provide richer accounts of the connections between domestic distortions, dynamic consistency, and optimal environmental policy.

\section{References}

Balassa, B., and Associates. 1971. The Structure of Protection in Developing Countries. Johns Hopkins University Press, Baltimore, USA.

Batabyal, A. A. 1987. Food, Population, and Employment in Post-Independence India: A NonMalthusian Perspective. Unpublished B. S. Honor's Thesis, Department of Agricultural, Resource, and Managerial Economics, Cornell University.

Batabyal, A. A. 1996a. Consistency and Optimality in a Dynamic Game of Pollution Control I: Competition, Environmental and Resource Economics, 8, 205-220.

Batabyal, A. A. 1996b. Consistency and Optimality in a Dynamic Game of Pollution Control II: Monopoly, Environmental and Resource Economics, 8, 315-330.

Batabyal, A. A. 1998. Environmental Policy in Developing Countries: A Dynamic Analysis, Review of Development Economics, 2, 293-304. 
Batabyal, A. A., and Beladi, H. 1999. A Dynamic Analysis of Environmental Policy in Developing Countries in the Presence of a Domestic Distortion. Unpublished Manuscript, Utah State University.

Bergsman, J. 1970. Brazil: Industrialization and Trade Policies. Oxford University Press, New York, USA.

Bhagwati, J. N., and Srinivasan, T. N. 1979. Trade Policy and Development, in R. Dornbusch and J. A. Frenkel, (Eds.), International Economic Policy: Theory and Evidence. Johns Hopkins University Press, Baltimore, USA.

Bhalla, A. S. 1992. Environment, Employment, and Development. International Labor Office, Geneva, Switzerland.

Bonetti, S., and FitzRoy, F. 1999. Environmental Tax Reform and Government Expenditure, Environmental and Resource Economics, 13, 289-308.

Brundtland, G. H. 1987. The U. N. World Commission on Environment and Development: Our Common Future. Oxford University Press, Oxford, UK.

Christainsen, G. B., and Tietenberg, T. H. 1985. Distributional and Macroeconomic Aspects of Environmental Policy, in A. V. Kneese and J. L. Sweeney, (Eds.), Handbook of Natural Resource and Energy Economics, Volume 1. North-Holland, Amsterdam, The Netherlands.

Dang, A., Goldstein, S., and McNally, J. 1997. Internal Migration and Development in Vietnam, International Migration Review, 31, 312-337.

DeJong, G. F., Abad, R. G., Arnold, F., Carino, B. V., Fawcett, J. T., and Gardner, R. W. 1983. International and Internal Migration Decision Making: A Value-Expectancy Based Analytical Framework of Intentions to Move from a Rural Philippine Province, International Migration Review, 17, 470-484.

Dixit, A. K., and Norman, V. 1980. Theory of International Trade. Cambridge University Press, Cambridge, UK.

Fanelli, J. M., Frenkel, R., and Rozenwurcel, G. 1992. Trade Reform and Growth Resumption in Latin America, in J. Fontaine, (Ed.), Foreign Trade Reforms and Development Strategy. Routledge, London, UK.

Golay, F. H. 1961. The Philippines: Public Policy and National Economic Development. Cornell University Press, Ithaca, USA.

Harris, J. R., and Todaro, M. P. 1970. Migration, Unemployment, and Development: A Two-Sector Analysis, American Economic Review, 60, 126-142. 
Johnstone, M. A. 1983. Urban Squatting and Migration in Peninsular Malaysia, International Migration Review, 17, 291-322.

Karp, L., and Newbery, D. M. 1991. Optimal Tariffs on Exhaustible Resources, Journal of International Economics, 30, 285-299.

Karp, L., and Newbery, D. M. 1993. Intertemporal Consistency Issues in Depletable Resources, in A. V. Kneese and J. L. Sweeney, (Eds.), Handbook of Natural Resource and Energy Economics, Volume 3. North-Holland, Amsterdam, The Netherlands.

Karp, L., and Paul, T. 1994. Phasing in and Phasing Out Protectionism with Costly Adjustment of Labor, Economic Journal, 104, 1379-1392.

Krueger, A. O. 1984. Trade Policies in Developing Countries, in R. W. Jones and P. B. Kenen, (Eds.), Handbook of International Economics, Volume 1. North-Holland, Amsterdam, The Netherlands.

Krugman, P. R., and Obstfeld, M. 1994. International Economics: Theory and Policy, $3^{\text {rd }}$ edition. HarperCollins College Publishers, New York, USA.

Lekakis, J. N. 1991. Employment Effects of Environmental Policies in Greece, Environment and Planning A, 23, 1627-1637.

Mehmet, O. 1995. Employment Creation and Green Development Strategy, Ecological Economics, 15, 11-19.

Miller, M. 1995. The Third World in Global Environmental Politics. Lynne Reinner Publishers, Boulder, USA.

Pindyck, R. 1982. The Optimal Phasing of Phased Deregulation, Journal of Economic Dynamics and Control, 4, 281-294.

Renner, M. 1992. Jobs in a Sustainable Economy, Worldwatch Paper \# 104, Washington, District of Columbia, USA.

Rodrik, D. 1988. Imperfect Competition, Scale Economies, and Trade Policy in Developing Countries, in R. E. Baldwin, (Ed.), Trade Policy Issues and Empirical Analysis. University of Chicago Press, Chicago, USA.

Schuh, G. E. 1982. Out-Migration, Rural Productivity, and the Distribution of Income, in R. Sabot, (Ed.), Migration and the Labor Market in Developing Countries. Westview Press, Boulder, USA.

Sen, A. K. 1975. Employment, Technology, and Development. Clarendon Press, Oxford, UK. 
Sen, A. K. 1980. Labor and Technology, in J. Cody, H. Hughes, and D. Wall, (Eds.), Policies for Industrial Progress in Developing Countries. Oxford University Press, New York, USA.

Simaan, M., and Cruz, J. B. 1973. Additional Aspects of the Stackelberg Strategy in Non-zero Sum Games, Journal of Optimization Theory and Applications, 11, 613-626.

Yang, X. 1993. Household Registration, Economic Reform, and Migration, International Migration Review, 27, 796-818. 